\title{
ENRICHING THE CONTENT PROVIDED BY CULTURAL CATALOGUES WITH DATA FROM INSTITUTIONAL REPOSITORIES
}

\author{
Á. Rodríguez Miranda ${ }^{\mathrm{a}, *}$, J.M. Valle Melón ${ }^{\mathrm{a}}$, M.C. Porcal-Gonzalo ${ }^{\mathrm{b}}$ \\ ${ }^{a}$ Laboratorio de Documentación Geométrica del Patrimonio - Grupo de Investigación en Patrimonio Construido \\ (University of the Basque Country UPV/EHU) \\ Nieves Cano 33, 01006 Vitoria-Gasteiz, Spain - ldgp@ehu.es \\ ${ }^{\mathrm{b}}$ Dept. of Geography, Prehistory and Archaeology - Grupo de Investigación en Patrimonio y Paisajes Culturales \\ (University of the Basque Country UPV/EHU) \\ Francisco Tomás y Valiente s/n, 01006 Vitoria-Gasteiz, Spain - mariacruz.porcal@ehu.es
}

KEY WORDS: Repository, Europeana, open access, research data, preservation

\begin{abstract}
:
Institutional repositories play a key role in universities and research centers for the preservation and dissemination of the knowledge generated or collected by these agents. Part of the information contained is related with Cultural Heritage and, therefore, it could be taken into account by thematic catalogues such as Europeana. In this paper, the opportunities and limitations of this connection are considered and presented by means of an ongoing case at the University of the Basque Country's institutional repository. In particular, we will deal with the information gathered about San Prudencio's Monastery (Clavijo, Spain), which includes a wide range of data from original datasets (photographs, pointclouds, coordinates, sketches and so on) up to finals results (reports, plans, 3D models, papers and so on).
\end{abstract}

\section{INTRODUCTION}

In the same manner as the rest of European countries, in Spain the open access movement has experienced a great development during the last decade. This movement stands for a rupture with the traditional form of reporting scientific information through publishers -since it encourages an access free of charge and directly by way of Internet- and states a twofold initiative based on the institutional repositories and the open access journals. The aim of this approach is that the knowledge generated in universities and research centers spreads quicker, more effectively and in a more accessible way for the society. First milestones of this movement go back to the Budapest Open Access Initiative (2002) and the Berlin Declaration (2003); in the EU's sphere of activity, this trend is contemplated by the OpenAIRE project.

Open access encourages self-archiving and the repositories maintained by universities and research centers help to meet this requirement in four different ways:

1. Providing tools and advice so as the staff can create contents more easily.

\section{Assuring long-term preservation.}

3. Storing the information (datasets and metadata) in accordance with standards and allowing interoperability.

4. Issuing the knowledge.
Information can be located in the webpage of each repository; however, this method is not very useful if users ignore whether the information actually exists where they are looking for. Rather, external users might obtain better results from search engines such as Google Scholar or RECOLECTA (for the Spanish case) which have indexed the repositories via the protocol OAI-PHM and provide a collective point of access to many of them.

However, these search engines are not able to capitalize on all the possibilities of retrieval given by the information and metadata stored in the repositories and, hence, there is an interesting research field on maximizing the access to the resources. Actually, it is this need for powerful access points what makes the link with catalogues so interesting for the repositories.

\section{IMPROVING ACCESS TO THE REPOSITORIES}

Non-contextualized textual searches are the most common way to locate information in a repository, that is to say, the user types a character string and the search engine tries to match it in any part of the description or the content available.

Better results would be obtained if it was possible to add some context, for instance, if we could indicate that the string is part of the title, part of the author's name, a place, a moment in time, etc; in doing so, we would not mix up concepts such as

\footnotetext{
* Corresponding author. This is useful to know for communication with the appropriate person in cases with more than one author.
} 
"The Washington Post” (journal), "Washington Irving” (writer), "Washington D.C." (city) and so on.

Another way of ameliorating the access to the items stored in repositories would be to give the users the possibility of navigating across the results, not only presenting a list with the hits but also plotting them on a map, along a timeline or a threedimensional space and allowing the users to explore and to select interactively.

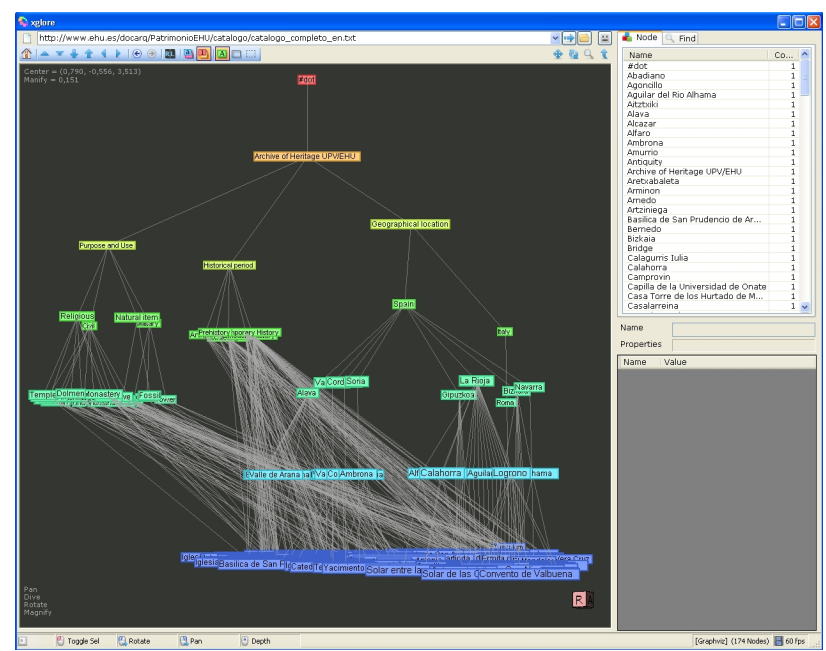

Figure 1. Interactive 3D-graph, the leaves at the bottom are linked with items stored in the repository (Rodriguez \& Valle, 2013)

Moreover, instead of waiting for the users, repositories could also play an active role in disseminating their information, in this regard, strategies such as syndication (e.g. RSS) might be most greeted.

Last but not least, the information stored in the repositories are suitable for being linked extensively as background or additional reading from external webpages such as journals, encyclopaedias or virtual classroom (e.g. Moodle, OpenCourseWare, etc) leaving at users' disposal to go further in their research.

\section{MUTUAL BENEFITS BETWEEN CULTURAL CATALOGUES AND REPOSITORIES}

In order to specify our argument to the field of cultural heritage, let us think of the searches in Europeana and how they can do part of the improvements listed in the previous section.

Figure 2 shows a map with the distribution of the matches of a particular search and was one of the possibilities of browsing the results provided by Europeana up to some months ago, together with the spreading along a timeline and the usual array of thumbnails. Nowadays (June 2013) there is a new interface and only the latter option is still given; however, latent though it may be, the real fact is that Europeana can manage both locations and dates.

Moreover, Europeana would provide the link with data stored in cultural organizations such as museums, libraries or archives; data about the very elements that have been considered in the institutional repositories.

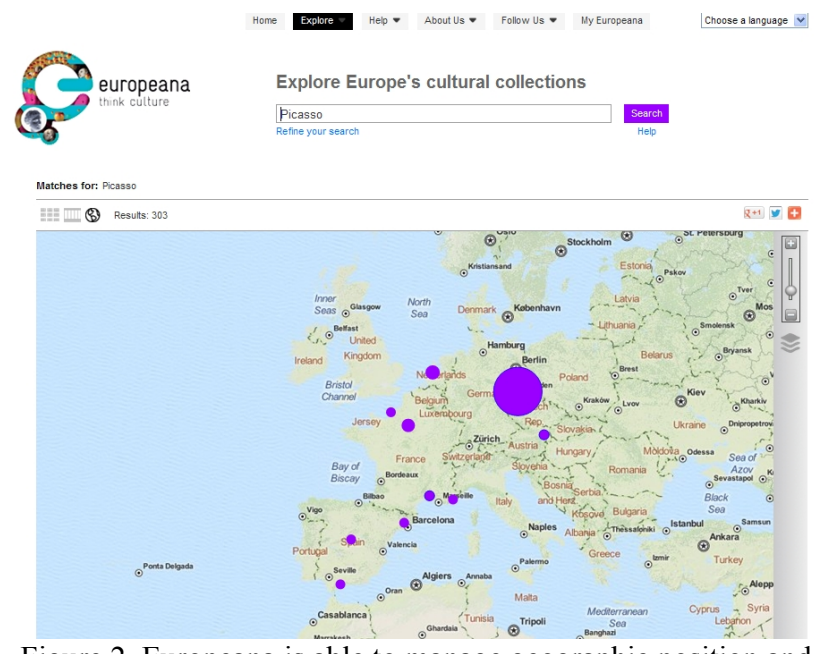

Figure 2. Europeana is able to manage geographic position and time in its searches.

Anyhow, we should not think that only the repositories benefit from the link with catalogues. Cultural catalogues might also take advantage of this relationship, not only because the repositories would increase significantly the amount of information available but also because the repositories dealt with more types of information that the ones that are usually considered by the catalogues (text, video, image, sound or 3D). In addition, repositories can provide deepness to the data since, as well as storing the final results, they can also include -and, actually, it would be most advisable to do so- the original data from which the results have been obtained and the whole trail of the processing, describing steps, additional information (e.g. sketches, certificates of calibration, ...) and properties of the results (such as the accuracy, the likelihood or the completeness); in doing so, users would be able to appraise the suitability of the data for their purposes and, eventually, they would be also able to generate brand-new results from the original data.

\section{SOME USEFUL CHARACTERISTICS OF THE REPOSITORIES AS SOURCES FOR CULTURAL CATALOGUES}

During the last years, several works have analysed the open access initiatives and the state of the repositories in Spain (Frías, 2006) (Estivill et al., 2007) (Melero, 2008) (Barrueco \& García Testal, 2009). Taking these analyses as basis, in this section we will look over some of the characteristics of the repositories that can be interesting in order to be linked from thematic catalogues.

Firstly, it must be underlined that for content creators (researchers, lecturers, technicians, students and so on) it is easy and quick to add their data to the repository given that they already have an infrastructure at their disposal. This infrastructure is a twofold system:

1. There is a hidden part (regarding the hardware, databases, standards for archival descriptions, management, budget for maintenance and so on) of which creators remain unaware. 
2. On the contrary, there is a visible part which includes the user interfaces, training and technical assistance in order to prepare and upload data.

Many times, library workers are in charge of the repositories, their advice and participation provide standardization to the processes of classification and the guaranty that the descriptions are done following quality and interoperability criteria.

Repositories carry out the task of preservation along with the one of dissemination, once uploaded to the repository, longterm preservation is delegated to the institution and the creators do not need to worry about this subject any longer. Moreover, as data is given permanent identifiers (doi, handle, etc) they can be referenced always in the same way.

Of course, not everything is advantageous in the repositories, there are also some drawbacks that deserve mentioning. Perhaps the most criticised one is the fact that the content is decided by the author and, consequently, there is a lack of external control, that does not mean that the quality of the information is poor but that it is not assured in itself; hence, it is necessary to resort to other criteria such as the author's career and prestige, the number of re-users of this particular piece of information (and the comments that the users have included reporting their experiences), citations in peer-reviewed journals, etc but, above all, it is fundamental that every new user can do the appraisal of the information by its own means. In order to allow user's appraisal, the information must be rich enough and include not only the main data -including precisions and warnings about existing gaps- but also the context and the justification of the decisions taken by the author during the processing.

Another feature that can reveal itself as a shortcoming is that individual creators cannot decide the metadata schema they will use to describe their information since they have to adopt the one used by the repository. As these repositories are designed for a wide variety of purposes there are not specific fields to store some kinds of metadata that can seem appropriate, in these cases, either we avoid these pieces of metadata or we resort to include them by using a detour (see below the way we have coded the geographic coordinates in the analysed case study). On the other hand, the use of Dublin Core is highly frequent since it is the standard expected by most of the harvesters and, hence, the easier way to be aggregated from external services.

A final hindrance of the repositories is that many authors are reluctant to use them; nevertheless, the huge work of information and training done specially by institutional libraries among the communities inside universities and research centers is gradually changing this situation.

\section{SAN PRUDENCIO'S MONASTERY ON MOUNT LATURCE, A CASE STUDY OF OPEN ACCESS FOR SCIENTIFIC PRODUCTION}

During the academic years 2009/10 and 2010/11 an ERASMUS IP activity was carried out with the participation of the National Technical University of Athens (Greece), the Universtiy of South Florida (USA), the HafenCity University (Germany), the Polytechnic University of Madrid (Spain), the Univesity of Siena (Italy), the Vilnius Gediminas Technical University (Lithuania) and the University of the Basque Country (Spain). The technical background of the participants covered the geomatics, the architecture and the archaeology, while the main goal of this activity was the exchange of experiences about the measure and representation of the Heritage and had a practical application at the ruins of San Prudencio's Monastery on mount Laturce (La Rioja, Spain).

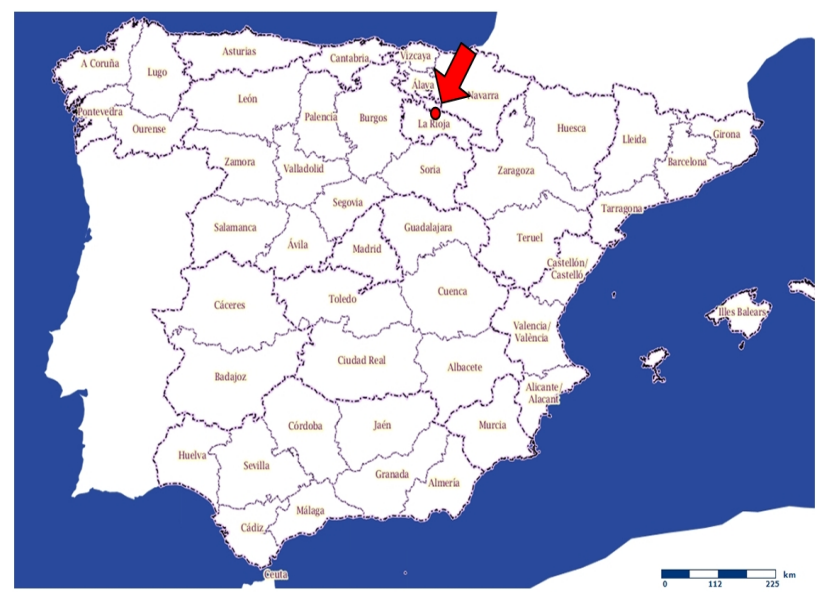

Figure 3. Location of the Monastery in the Iberian Peninsula

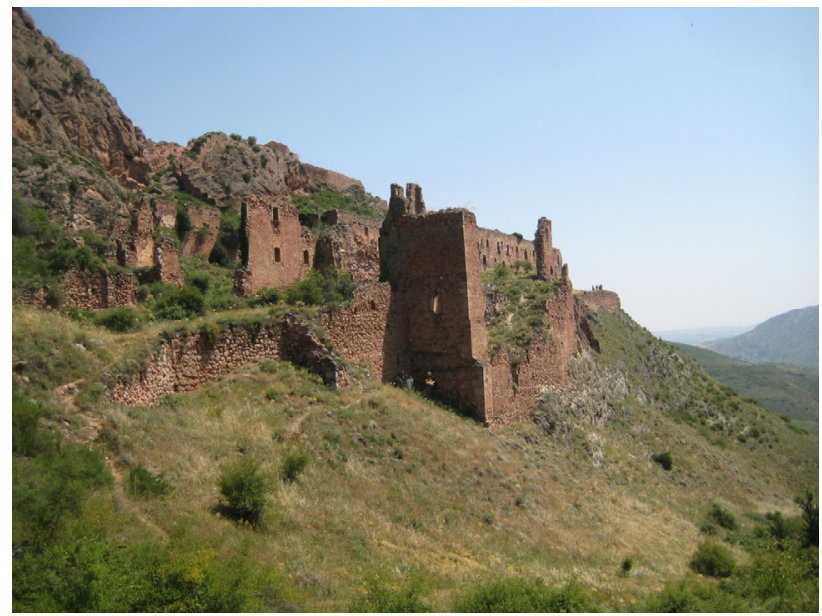

Figure 4. Ruins of San Prudencio’s Monastery

The fieldwork was arranged in multinational groups of 4-5 students who practised with photogrammetric cameras and two models of 3D laser scanners (medium and long range), always under the supervision of one professor in charge. Then, during the office work, the information was processed in order to show the procedures and try to get some preliminary results.

As all the activity lasted for only two weeks each year, very little processing work could be done; as a consequence, we decided to focus on learning aspects and to give less attention to the fact of obtaining final results. This further processing could be done in case some students would like to go on with the project, for instance, in the course of their bachelor theses.

All along the accomplishment of this activity, the information was managed by means of a virtual classroom restricted to the partners; however, once finished the academic part it was planned to give open access to all the relevant information gathered. For this goal it was decided to use the University of the Basque Country's institutional repository (ADDI) according to the following structure: 
- One item describing the academic activity which includes the application form, the preparation of educational materials, fieldwork, safety plan, program for the cultural visits, tourist information and so on.

- A database with the geometric information recorded on site (photographs, point clouds, etc) with all the additional information that an external user would need in order to re-use it.

- Students' master theses on geomatics and archaeology (see figures 6 and 7), each one includes additional datasets and results (analyses, plans, 3D models and so forth).

- Scientific papers related with any of the previous ones.

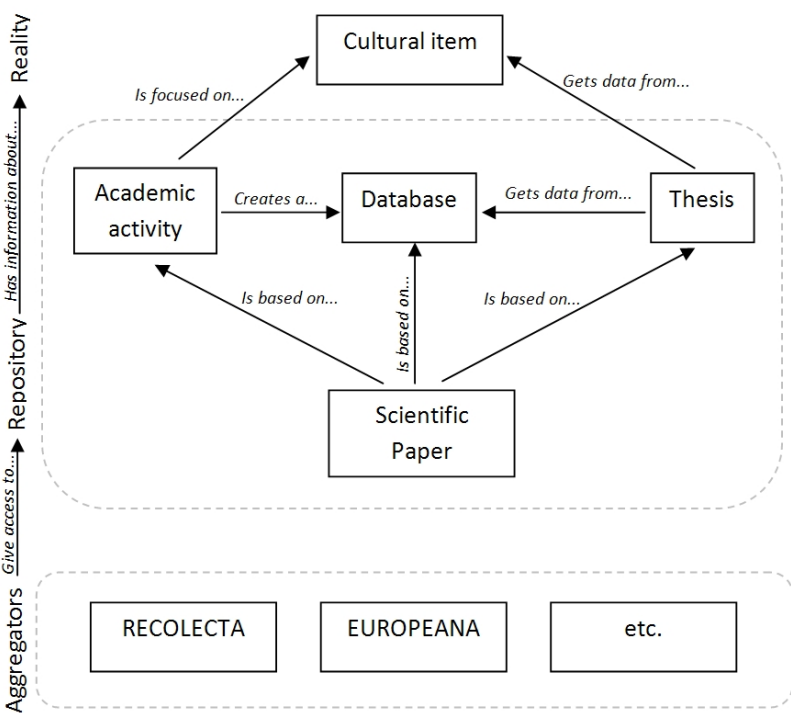

Figure 5. Structure of the information stored inside the repository

Each record is described by means of a set of metadata, which must be as clear, precise and complete as possible. Figure 6 shows an excerpt taken from the repository, this one runs on DSpace and uses a schema based on qualified Dublin Core.

As it can be seen, multilinguism is accepted and the descriptions are rich enough for allowing some semantic use of metadata (both from the meaning of the DC tags and, in some cases such as on the right part of "dc.rights" and "dc.type", due to the use of concepts collected in namespaces), although this possibility is not very utilised yet by the usual search engines that explore the repositories.

Interoperability with other sources is improved if descriptions are filled in following a series of criteria, for instance, using thesauri for keywords. Moreover it is possible to code coordinates for spatial location and time. Again we are in front of possibilities allowed by the description but not included in the search engines that nowadays access the repositories. Nevertheless, as said above, they are contemplated by Europeana.

For example, there are some elements of the description that can be used to mark relevant dates such as the moment the data was generated (dc.coverage.temporal), when the project finished (dc.date.issued) or when it was published (dc.date.available).

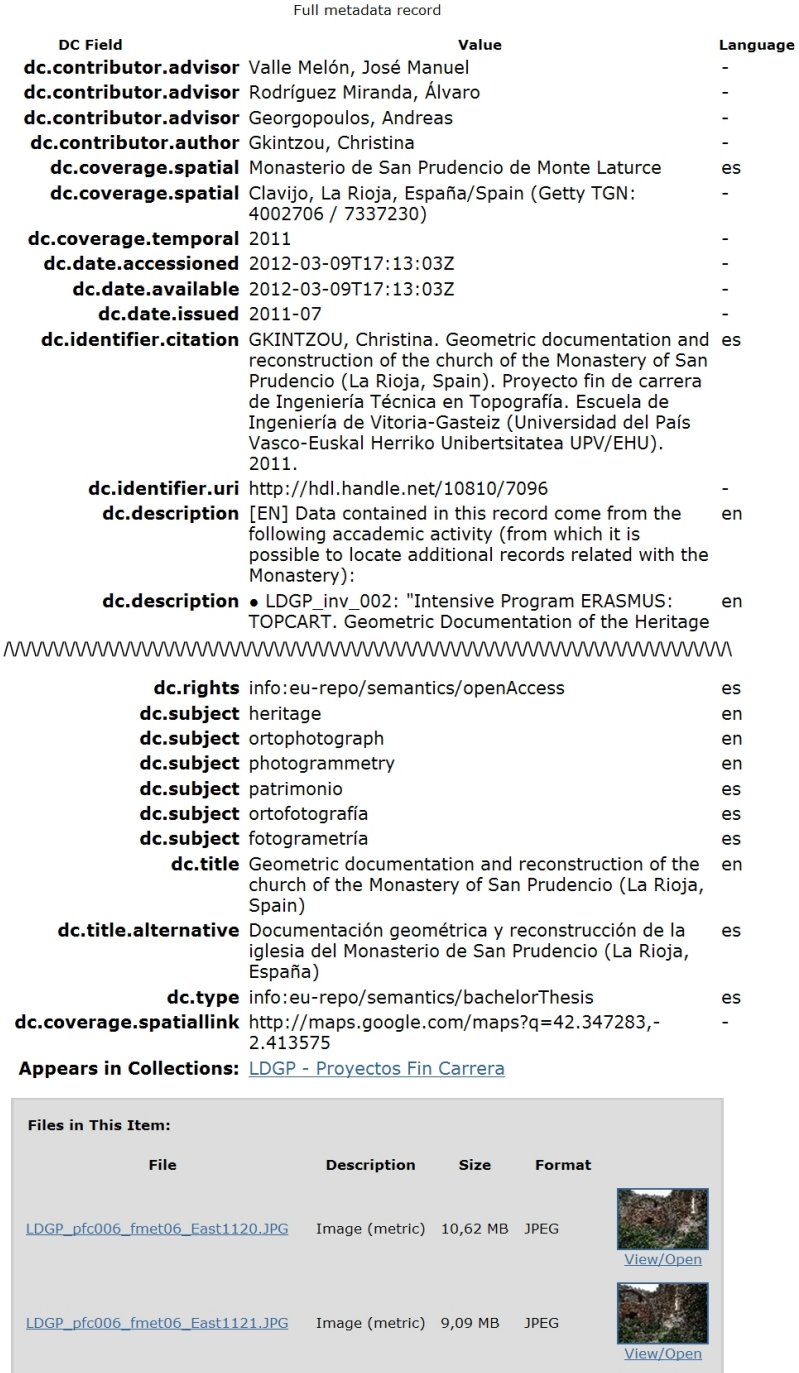

Figure 6. Part of the metadata included in a record from the University of the Basque Country's repository (http://hdl.handle.net/10810/7096 20 Jun. 2013)

Concerning the spatial location, the example shown in the figure uses several instances of the field (dc.coverage.spatial). The first one refers the cultural item (in this case the San Prudencio's Monastery on mount Laturce); it would be convenient to link this term to an authority record, like this, it would be possible to relate it with more pieces of information about the same cultural item that are located in other repositories. However, nowadays no authority file is recognized for this duty; in the meantime, perhaps it would be possible to link with the entry in DBpedia (a semantically structured database obtained from Wikipedia), however, this point needs further considering.

The second label (dc.coverage.spatial) shows the administrative division where the cultural item is (municipality, region and country); of course if, due to its extension, more than one municipality or a bigger administrative unit are needed it is possible to store them. We have included the official name and a reference to a thesaurus, in this particular case the Getty TGN.

Finally, a last mention to the placement is given by means of coordinates (dc.coverage.spatiallink, at the end of the list). We have used a link to Google's map viewer; by doing so, as well 
as creating the link to a map we avoid the need to explicitly state the reference system since it is clear that we are adopting the one used by the viewer (latitude and longitude in WGS84). In any case, do note that, regardless of this general reference of the position -as a single point- included here for classification purposes, maybe some of the files contained in the record will be maps or $3 \mathrm{D}$ models which will use different coordinate systems.

As for the types of information stored in the record, it is possible to add several files, in the particular case of an example of geometric documentation of a cultural element, these files could be:

- Datasets (original point clouds, photogrammetric pairs, etc).

- Technical and auxiliary data (certificates of calibration, sketches, coordinates of the control points, etc).

- General report detailing the main goals of the project, the context and the description of the processes followed during fieldwork and office work.

- $\quad$ Final results (plans, 3D models, animations, etc).

- Notes about the limits of the copyright, re-usability, disclaimer of responsibility and anything related with the legal status of the information.

It is essential that all this information is placed together so as the user can evaluate the results, understand the project as a whole and re-use the raw data for different purposes. The following image shows an example which counts on a descriptive report, the different kind of results (VRML files, CAD and videos) and the original data, in this case, metric photographs.

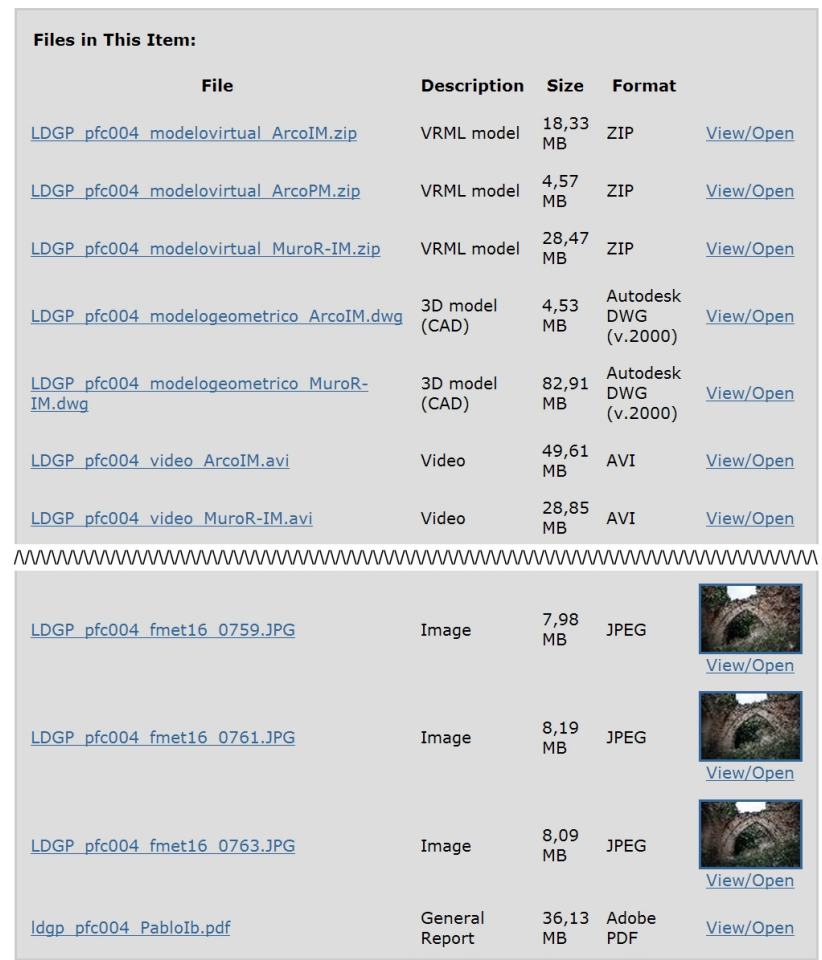

Figure 7. Different types of files included in a record (http://hdl.handle.net/10810/7083 20 Jun. 2013)
Regarding file formats, it must be taken into account that this information falls into the category of dissemination packages according to the terminology used in the OAIS model (CCSDS, 2012). As long as possible, proprietary and complex file formats have to be avoided; although sometimes, for the sake of the data transfer rate and the size limits, we need to resort to compressed versions (e.g. ZIP files).

Nowadays, the uploading is underway since it is necessary to prepare it so as it can be interpreted by new users. On the other hand, there are some outcomes still in progress that will be included as soon as they will be completed. Anyway, there are already some contents available which can be located, as a first option, by doing a query inside the own repository (https://addi.ehu.es/simple-

search?query $=$ monasterio + San + Prudencio); however, according to what it has been said about the different ways of getting access to data stored in repositories we are working on connecting this information by means of aggregators, external webpages and so on with the aim of improving its use.

For instance, next figure shows the search page of HISPANA, which is the main Spanish aggregator of cultural content (in June 2013 it gave access to more than 4,500,000 digital objects from 197 repositories) and it is also one of Europeana's providers (by the same time, a selection of more than 2,000,000 items from 64 of the repositories indexed in HISPANA were also accessible through Europeana).

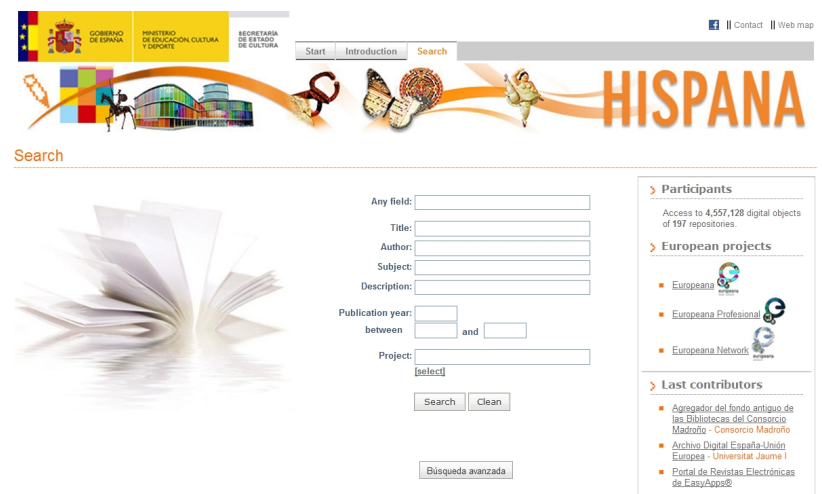

Figure 8 . Searching cultural content by means of HISPANA (http://hispana.mcu.es)

In order to check the utility, we try doing a search with the string "Laturce" (since a search about "San Prudencio" might be too general) and we get the following results (June 2013):

- 5 records about the ERASMUS project from the University of the Basque Country's repository.

- 3 items from the Virtual Library of La Rioja (these ones are also accessible through Europeana): one xylography of 1845 , a legal proceeding of 1729 and a digitised book of 1908 .

- 4 records from other repositories not contemplated in Europeana ( 3 papers and another digital copy of the book of 1908).

Moreover, the search also returns links to the hits in Europeana that come from aggregators other than HISPANA (in this case, 2 records from the Complutense University of Madrid aggregated though the European Library). 
Consequently, even if nowadays most of the institutional repositories are not directly accessible from Europeana, there is still the possibility of doing common searches by means of the national aggregator. In due course, HISPANA might consider that some pieces of information stored in institutional repositories are suitable for being presenting also through Europeana and give them a wider diffusion.

In the meantime, there is a huge work to do: as shown in the example, only a few records among the scores of them that should exist about the Monastery were located, therefore, it is necessary to link with more sources of information (e.g. archives) and provide more powerful search tools.

\section{CONCLUSIONS}

The presented case study reports an activity focuses on the study of a cultural element which generated an asset that can be useful for different purposes such as research, learning or cultural promotion. It is conceived as an open access initiative and supported by the institutional repository on which we rely in order to ensure the long-term preservation, the visibility and the interoperability of the solution.

It is impossible to avoid mentioning that today's economic situation is producing huge changes in the way we have considered the information about cultural elements. At least in several European countries, the possibilities to get new datasets will be limited for the following years; this fact highlights the necessity of preserving the information already obtained and maximizing its use.

Digital information is always at risk of disappearing due to its fragility. Institutional repositories are a powerful service provided by universities and research centers that might help in the difficult task of preservation; anyway there is no point in preserving if there are not any re-use of the data, it is here where the opportunity given by the combination with thematic catalogues is clearer.

Institutional repositories define a decentralized archival system which can house a great amount of information capable of being located by means of thematic catalogues. On the other hand, the repositories are rather easy to use for the creators and they are maintained by the universities and research centers, for these reasons, they are a quick and accessible way of creating contents.

In the case of cultural catalogues, such as Europeana, this relationship will give to the repositories a set of powerful tools for searching that they lack nowadays, it will make possible to use the semantic potential of the descriptions and the location in space and time, additionally, it will link with the contents already provided for the rest of the cultural organizations that are included in the catalogues.

On the other hand, cultural catalogues will also be enriched significantly not only in terms of the amount of information but also because the type of information that can be stored in the repositories is manifold and considers the project as a whole from the original data to the final results.

\section{REFERENCES}

Barrueco, J.M., García Testal, C. 2009. Repositorios institucionales universitarios: evolución y perspectivas. In: XI Jornadas Españolas de Documentación Fesabid 2009 (Zaragoza, 20-22 Mayo 2009), pp. 99-107. http://www.fesabid.org/zaragoza2009/actas-fesabid-2009/99107.pdf (8 Apr. 2013)

Berlin Declaration. 2003. Berlin Declaration on Open Access to Knowledge in the Sciences and Humanities. http://oa.mpg.de/files/2010/04/berlin_declaration.pdf (4 Apr. 2013).

Budapest Declaration. 2002. Budapest Open Access Initiative. http://www.opensocietyfoundations.org/openaccess/read Apr. 2013).

CCSDS. 2012. Reference model for an Open Archival Information System (OAIS). http://public.ccsds.org/publications/archive/650x0m2.pdf $\quad(20$ Jun. 2013).

Estivill, A. et al. 2007. Uso de metadatos en depósitos institucionales españoles: una primera aproximación. In: X Jornadas Españolas de Documentación Fesabid 2007 (Santiago de Compostela, 9-11 Mayo 2007).

FECYT. RECOLECTA - recolector de ciencia abierta. http://www.recolecta.net (4 Apr. 2013).

Frías, J.A. 2006. Las universidades españolas y la iniciativa $O A I$. In: Repositorios institucionales: una vía hacia el acceso, la visibilidad y la preservación de la producción científica. Jornadas OS-Repositorios (Zaragoza, 14-15 Diciembre 2006).

Getty TGN. Getty Thesaurus of Geographic Names. http://www.getty.edu/vow/TGNSearchPage.jsp (4 Apr. 2013).

HISPANA. http://hispana.mcu.es (20 Jun 2013)

Melero, R. 2008. El paisaje en los repositorios institucionales open access en España. BID: textos universitaris de biblioteconomía i documentació, $\mathrm{n}^{\circ} \quad 20$. http://www2.ub.edu/bid/consulta_articulos.php?fichero=20mele r4.htm (6 Apr. 2013).

OpenAIRE. Open Access Infrastructure for Research in Europe. https://www.openaire.eu (4 Apr. 2013).

Rodríguez A., Valle J.M., 2013. Propuesta para acceder a los recursos sobre Patrimonio depositados en el repositorio institucional ADDI de la Universidad del País Vasco (UPV/EHU) mediante un grafo $3 D$ interactivo. http://hdl.handle.net/10810/9865 (4 Apr. 2013).

\section{ACKNOWLEDGEMENTS}

The origin of the information presented in this text is an ERASMUS IP funded by the European Commission through the Spanish OAPEE (Organismo Autónomo de Programas Educativos Europeos), this activity was given the following identifiers: 2009-1-ES1-ERAIP-0013 and 2010-1-ES1-ERA100024. 